\title{
The Creative Corporation: Spontaneous Order in the Enterprise
}

\author{
Thomas N. Duening, PhD \\ El Pomar Chair of Business \& Entrepreneurship \\ University of Colorado Colorado Springs \\ 1420 Austin Bluffs Parkway \\ Colorado Springs, CO 80918, USA
}

\begin{abstract}
This paper is written in response to increasing calls around the world for large enterprises to become more creative in their core business operations. However, most of the research into enterprise creativity is based on the assumption that creativity (or 'innovation') can be managed like any other function. This paper builds on the work of F.A. Hayek to argue instead that creativity is not an operational function, but rather an aspirational outcome. To enhance overall enterprise creativity managers need to create internal environments that enable what Hayek refers to as 'spontaneous order' to arise. The greatest engine of creativity ever devised by humans, Western capitalist economic structure, is Hayek's prime example of how outcomes are often the result of human action, but not necessarily of human design. The article concludes with action steps managers can take to enhance their enterprise creativity.
\end{abstract}

\section{Introduction}

The modern era of global competition has introduced a new imperative for corporate innovation. Innovation is often cited today as a primary source of competitive advantage regardless of industry or national identity. A Google search on the terms 'innovation imperative' returns no fewer than 80,000 hits. ${ }^{1}$ Clearly innovation is shaping the modern economy, but was it ever not so? Perhaps our generation suffers from the same myopic perspective as generations of the past who tended also to think that their generation was one of profound innovation and change. The argument has been made that our generation is unique in that only recently have we developed global communication networks, global transportation systems, and massive online education systems. These and other factors have also served to make 'place' less important as a factor in one's access to key knowledge, talent, and other resources essential to innovation. An innovation in one part of the world is now rapidly disseminated via the Internet and other channels to nearly every other place in the world. As such, it is difficult for any particular innovation to be sequestered or harbored by a single individual or firm. Once the genie is out of the bottle, so to speak, any other intrepid company or entrepreneur can leverage the same innovation for commercial purposes. Intellectual property protection can help build a 'picket fence' around some innovations, but global competitive advantage is not as reliant on intellectual property as it once was.

Perhaps, then, what makes our era unique is not the fact of innovation being an important driver of competitive advantage, but rather that the velocity of innovation has increased. Arguably, this is the vital distinction between the modern era and its 'innovation imperative', and the past where innovation was also important to commercial success (try to name an era where innovation was not important). Perhaps what matters most today is not that a company innovates, but rather that it increases the velocity of its innovation.

This paper argues that in order to compete in this rapidly evolving 'innovation economy' it is no longer possible for organizations simply to 'keep doing what they have always done'. Past managerial imperatives-Six Sigma, reengineering, TQM, and others - have limited value as contemporary guideposts. Managers need to improve operations to be sure, but if that is their sole focus they can be certain they will improve themselves inexorably into irrelevance. Focusing on doing better what the organization already does will not cut it in our fast-paced, globally competitive, innovation-based economy.

\footnotetext{
${ }^{1}$ Search conducted on October 30, 2018.
} 
Innovation is defined in this paper asthe ability to solve new or old problems in new ways. Creativity plays a role in innovation to the extent that innovation requires insight into how a problem can be solved in a new way. It is this 'insight' that lies at the heart of the 'creative moment'. Elsewhere, the creative moment has been defined as the 'eureka' or 'ah ha' moment (Murphy, 1984).Readers have probably experienced this phenomenon. This 'creative moment' likely followed hours, days, weeks, or even years of false starts, frustration, and dead ends. Yet, the problem was solved. What needs to be understood is what was happening during the hours, days, weeks, or years that proceeded the creative moment. What was the organizational context of the 'creating'. What were the processes that enabled the creative insight? What role does other people e.g., colleagues, managers, others play in the creative process? That is what we will explore in this paper.

In the next section we will explore a more in-depth definition of 'corporate creativity' so that we can better grasp what we are trying to understand and promote. The ultimate aim of this paper is to operationalize 'corporate creativity' and to give readers tactics to use immediately in their workplaces. It would be beneficial toward this end to have at least a modest grasp of what we are talking about.

Next, we will examine some 'best practices' that are associated with corporate creativity. There is no such thing as a 'last word' on this topic, but it is helpful to know what some of the top scholars and practitioners of corporate creativity are thinking and prescribing.

The paper then engages in a short discussion about how creativity manifests in society writ large. The paper draws insights into corporate creativity from the most powerful creative engine humans have ever devised: Free market economies. We will explore, in particular, Hayek's notions of the spontaneous order and abstract rules. It is difficult (or, impossible) to find a social system that has produced more creativity, more timely creativity, and more prosperity than free market economies. This paper assumes that the seminal ingredients of creativity are best evidenced in such free-market systems. Although corporations are more goal-oriented than society writ large, we would be remiss if we didn't investigate this powerful creative engine for potential links to corporate creativity.

Finally, this paper concludes with key take-aways that will guide managers and corporate leaders who want to nurture a more creative corporate culture. Ultimately, this paper argues, the foundation of a creative corporate culture must include potent abstract rules that help produce what is referred to as a 'bounded spontaneous order'. Paradoxically, although creativity is desperately desired, it cannot be commanded. It can only be beckoned.

\section{Defining Corporate Creativity}

It is usual to define key terms by citing how those terms are defined in leading dictionaries. I'll spare you that here because creativity may be one of those terms that we all understand and know, but find it difficult to pin down into a simple or singular definition. Let's therefore begin by attempting to highlight some factors that seem to be part of any creative moment. I propose the following:

- Creativity is evidenced by novelty

- Creativity often involves combining well-known particulars in a new way

- Creativity usually occurs only after hard work or lengthy preparation

- Creativity often produces unusable or worthless outcomes

- Creativity can come from anyone and anywhere

- Creativity is more likely under duress, stress, or scarcity

- Creativity can involve luck and non-predictable contingencies

Below, I take a deeper look at each of these factors:

Creativity is evidenced by novelty: It would be difficult to identify something as creative if it was not also novel. We tend to see ideas, products, designs, as creative if they are of a type that we haven't seen before. Of course, this does not mean that the creative idea isn't being concurrently developed elsewhere. In the global economy, it's likely that any creative output is either already being developed or is close to being developed somewhere else. Still, novelty is relative to people and markets, and there is no need to worry about 'absolute novelty'. What matters most in this innovation economy is to capture creative moments as they occur and leverage them for competitive advantage with deliberate speed. 
The old concept of 'sustainable competitive advantage' is inexorably losing its relevance in the innovation economy. What matters more is continuous novelty creation, creativity capture, and leveraging creativity for what might be called 'sustainable creative advantage' (SCA). ${ }^{2}$

Creativity often involves combining known particulars in new ways: Writers, artists, musicians, all work with limited tools, materials, and time to create new works. Writers have words, punctuation, and limited forms of media (although digital media has recently opened new vistas). Good writers combine words and punctuation marks - elements known to us all - in novel ways. We know a good writer when we read one, but that doesn't mean we can define, exactly, what makes them 'creative'. In fact, the nebulous character of the term has enabled the profession of 'literary critic' and endless interpretations of the creative works of writers. Certainly, there are writers (or other types of artists) that continue to be revered for their creative genius. But that doesn't mean that writing is finished or that there won't be new writers that will win accolades as creative geniuses. Knowing this, it's important to realize that corporate creativity may involve little more than re-combining the resources that the organization already controls. With this understanding, the key is to help people become aware of the resources that are within their realm of control in order to enable creative re-combination of the resource pool. How often have large companies lamented the organizational 'silos' that inhibit cross-boundary communications and awareness? Creativity is usually not cited as a casualty of these silos. But, given that creativity is often the result of the re-combination of existing resources, it is likely that corporate creativity suffers in organizations rife with silos.

Creativity usually occurs only after hard work or lengthy preparation: Many people assume that creative geniuses are gifted by genetics or something else outside their control. That is a myth. Creative people are more likely to point to the hard work, discipline, practice, and years of effort that lies behind momentary, spontaneous acts of creation. Research into what it takes to develop expertise in nearly any field has identified 'deliberate practice' as necessary. Deliberate practice is the term used to refer to the rehearsal of activities, collection of feedback on the quality of the performance of that activity, analysis of the feedback, and use of the feedback to improve on future performances (Day, 2010). Significantly, the research has determined that expertise development in nearly any field requires ten years of deliberate practice (Ericcson, Prietula, \& Cokely, 2007). So, creativity, although manifested as a singular 'ah ha' moment is normally the result of deliberate practice and hard work. Austrian economist Von Mises (1949, pp. 139-140) wrote about the creative genius as follows:

"Neither does the creative genius drive immediate gratification from his creative activities. Creating is for him agony and torment, a ceaseless excruciating struggle against internal and external obstacles; it consumes and crushes him...Such agonies are phenomena which have nothing in common with connotations generally attached to the notions of work and labor, production and success, breadwinning and enjoyment of life... The genius does not deliver to order. Men cannot improve the natural and social conditions which bring about the creator and his creation...But, of course, one can organize society in such a way that no room is left for pioneers and their pathbreaking."

Creativity can come from anyone and anywhere: This point resonates with the one immediately above. With enough hard work, practice, feedback, and rehearsal it is possible for anyone to develop creative capacity. The key to enabling employee creativity is to ensure that everyone not only recognizes they are free to exercise their creativity, but also that they will be duly recognized and rewarded for their contributions. Too often employees are reluctant to express their creativity because someone else - often their immediate superior - will get the credit (or doesn't get the credit and retaliates against the subordinate for standing out). There is probably little more an organization could do to stifle creativity than to reserve credit only for those with lofty titles and higher pay grades.

Creativity is more likely under duress, stress, or scarcity: In times of stress or scarcity, people often discover creative solutions that they would not have thought of under other circumstances. While it is difficult to create a survival mindset in the corporate workplace, there clearly is value in creating an 'us against the elements' mentality among the corporate team. Anyone who is a sports fan recognizes this mentality as a common, nigh unto cliché, sound bite for athletes and sports teams to motivate high performance.

\footnotetext{
${ }^{2}$ Although a search of the scholarly literature brings up 867 citations for 'sustainable competitive advantage' there are zero citations for the phrases 'sustainable creative advantage' and 'sustainable innovation advantage'.It seems that a sea change is in order to respond to changes in the actual world of business and competition.
} 
Keeping employees focused on key metrics, competitors, and global challenges may help generate a similar 'survivalist' mentality that will help motivate creative efforts.

Creativity can involve luck and non-predictable contingencies: There is no denying the role that luck plays in nearly any achievement. The creative person recognizes this, grows comfortable with it, and learns to leverage every lucky stroke that comes his or her way. There is no 'pride of ownership' or ego that requires credit for fortunate happenstance. Creative people 'go with the flow' and don't worry about whether their success is based on luck or hard work. At the same time, recognizing that luck plays a role in anyone's ultimate creative success should engender both humility and gratitude. Humility is an under-appreciated value in corporations.Most people confuses humility with deference or reticence. We are not talking here about creating a workplace full of shrinking violets - quite the contrary. Without significant achievement, there is nothing to be humble about. Gratitude is similar to humility except that the former is a social act. Demonstrating gratitude for the lucky circumstances that helped one enjoy the fruits of a creative moment helps to maintain the social equilibrium of the corporate culture. This is critical to cultivating a culture capable of competing based on continuous creative advantage.

\section{Best Practices in Corporate Creativity}

Creativity is one of those 'soft' concepts that many hard-nosed business people look upon with skepticism. Creativity is often associated with 'starving artists' and others who have no concern for commerce. Businesses cannot afford to adopt that frame of mind, and they cannot afford overhead that doesn't somehow contribute to the organization's financial health. For example, one of the more often-cited techniques to nurture creativity within the corporation is referred to as 'tinkering time'. Google has a well-known " $20 \%$ time" initiative where employees are encouraged to spend 20 percent of their time working on projects outside their job description (Finkle, 2012). However, research into the effectiveness of this approach indicates serious problems. The problem companies have found with 'tinkering time' as a general policy is that most employees are not comfortable with the burdens and expectations of tinkering time. They find the requirement to 'be creative' as an unwelcome burden on top of their regular job requirements (Foege, 2013).

Creativity in the corporate context requires that it be channeled either to revenue-generating activities or to costreducing activities. That is to say, creativity within the organizational context cannot be free-flowing and without consequence. It must be disciplined, channeled, rule bound. We will take up the notion of rule-boundedness in the next section. Here, we will be concerned some 'best practices' associated with nurturing a creative corporate culture. Fortunately, there is ample research into factors that are vital to fostering a creative climate in the organizational setting. Ekvall's (1996) model of the creative climate identifies ten factors that need to be present:

1. Idea time: People need time to think and to develop new ideas. Many organizational cultures frown on this as they tend to see 'think time' as 'idle time'. Creative ideas need time to incubate. People may even need time to do some reading that helps them understand their creative ideas in more depth and to gauge the true novelty of what they are considering.

2. Risk taking: People need to be able to make decisions within acceptable risk boundaries. However, most organizations don't articulate risk boundaries clearly enough for people to feel comfortable in their decision making. Some organizations, such as Koch Industries, specify domains in which people have specific 'decision rights' and they are empowered to follow their own thinking and instincts in taking risks within those boundaries. Repetitive success with specific decision rights helps an individual acquire additional such rights over time and with continued success (Koch, 2007).

3. Challenge: People need to feel challenged within their own areas of expertise. Csikszentmihalyi's work on the concept of 'flow' indicates that people work at their peak when they are offered challenges that are achievable, but that require they stretch their talents to new levels (Csikszentmihalyi, 1990). Further, Duening and Ivancevich (2001) highlighted the need for the organization's 'Einsteins' to be challenged in a manner that helps them achieve the highest levels of Maslow's hierarchy of needs.

4. Freedom: People need freedom (I prefer 'autonomy' in the corporate context) to express their talents, make mistakes, learn from mistakes, and grow within their field of expertise. Some managers have a tendency toward too-soon interventions and tend to thwart the essential learning and unlearning that only comes from experience. 
5. Idea support: People need to feel that their ideas are aligned with the interests of the organization. Organizations should establish clear objectives and clear contact points for individuals to discuss their ideas as they develop and to ensure that they are aligned with the long-term interests of the organization.

6. Conflicts: People need to be able to defend their creative ideas within the organization's marketplace of ideas. Managers should articulate that there are no entitlements within the organization, and that all ideas must live or die based on their relative merit within that marketplace. At the same time, people should be empowered with business case development and presentation skills that enable them adequately to articulate their creative insights within the context of the idea marketplace.

7. Debates: People should be engaged in debates about the merits of their creative ideas. Debating serves two primary purposes: 1) It forces the creator to think hard about possible objections/problems with their creative ideas; and 2) It introduces incremental improvements to ideas from those who are party to the debates.

8. Playfulness/humor: Our inclination as adults, who largely have sublimated our ability for imaginative play, is to separate work and play. Naturally, we are not suggesting that the workplace should be turned into a playground, but there are several very important consequences of enabling some play activity in the workplace. Play by its very nature is spontaneous, open ended, and creative. Among children there is no need for elaborate toys, play structures, or organizational rules to initiate play. Children have little trouble inventing games with others and creatively altering and adjusting the rules as they proceed. Play, in fact, often is inhibited by preexisting rules. When asked about play, children often indicate that it is best when there is no adult supervision. While adult play, such as professional sports, is definitively rule-governed there is also an aspect of balance that intuitively arises. Professional sports that are 'overly officiated' or where the rules begin to encroach upon the spontaneity of the interaction become objects of derision and controversy. Play in the workplace, if it is to enhance innovation and creativity, must avoid being overly governed by oppressive rules. Of course, employees should 'play' within the context of some rules that align with organizational strategies and objectives.

9. Trust/openness: People function at their best within a context of trust and openness. This means that managers and others don't 'sugarcoat' their responses to creative ideas, overstate their interest in ideas, or understate their interest. They also avoid any 'not invented here' envy or jealousy that often sabotages relationships and the potential further development of good ideas.

10. Dynamism/liveliness: People today tend to want to minimize the distinction between work and play. Organizations that foster open spaces, free-flowing conversations, impromptu chat sessions, and favor a lively workplace 'buzz' are the norm among today's most creative companies. Think Facebook, Google, Ebay, and other titans of our time. They famously have created lively organizational environments that are equal parts work and play.

These ten factors have been the subject of substantial research and there are some prescriptions about how to foster them within the organization and how to mix a recipe that is tailored to different types of organizations. For example, creativity within a steel mill will take on a different look and feel than creativity within an advertising agency. Under these two examples, clearly the relative importance and emphasis on these various factors will differ. As I pointed out elsewhere, the ingredients for organizational improvement are well-known. What is less intensively researched and, thus, less well known is how to mix these ingredients into a recipe that is right for particular organizational settings (Duening, 2007). The best that can be said right now is that managers must creatively mix these ten ingredients and discover the recipe that is best for their particular organization.

\section{Abstract Rules and Corporate Creativity}

Life is governed by rules, not all of which are articulated or codified. Often times we only have a vague notion that our actions are governed by rules, and we might even have difficulty answering a question about why we have taken specific actions. Myriad such 'abstract rules' govern our mundane as well as our more important daily activities and decisions (Hayek, 1978).Abstract rules are those unarticulated, yet essential, guidelines, norms, traditions that people within a social setting tend to follow. Abstract rules are often unarticulated; they aren't explicitly written down or codified. Still, most social systems could not function without them. For example, the busy sidewalks of major cities could not function if pedestrians did not follow the abstract rule of trying to avoid direct, head-on collisions with other pedestrians. The abstract rule to avoid collisions can basically be worded as 'stay to the right in the direction that you are walking and move further to the right if you are on a head on course to collide with someone walking in the opposite direction'. Wayward pedestrians who violate this rule (a more 
common occurrence in our 'text messaging' age) are a nuisance to others and a hazard to themselves (Painter, 2012).

If we can accept the premise that social groups require abstract rules to function effectively, then the question that arises is: 'Where do these rules come from?'We can turn to the work of Friedrich Hayek for an insightful and carefully analyzed answer to this question as it pertains to abstract rules that govern social activities in a society writ large.

Hayek's most trenchant analysis of the phenomenon of rule-governed social behavior identifies rule following as a phenomenon that lies between what he categorizes as 'instinct' and 'reason' (Hayek, 1988). He points out that most of the rules we follow originally were based on instinctive activities that humans engaged in without thinking. Some of these behaviors worked, and some did not. Accepting the scientific understanding of humans as evolved beings that formerly lived primarily in nomadic groups of one hundred or so members, it is easy to understand that such groups who tended to adopt the most useful behaviors and activities were more likely to survive and, potentially, to thrive (Hayek, 1973). Eventually, as language and writing evolved, humans developed the capacity to reflect on the activities and behaviors that worked. These behaviors and activities might have been codified into formal rules (such as a national constitution) or they may simply have been passed on through oral traditions and stories.

The important point to note about this brief history of the origin of at least some of our more useful abstract rules is that they are not a result of reasoning about what works. Reason played no role in the emergence of the abstract rules. Abstract rules emerge out of people acting on 'instinct' and creating new activities based on the conditions and contingencies under which they find themselves. Some of these new activities prove fruitful and are repeated and perhaps refined; others prove less useful (and occasionally fatal) and therefore arenot passed on. Reason comes into play only after the new rules have emerged and proven to be useful (Hayek, 1948).

Reason is our capacity to articulate formerly abstract rules in the prevailing natural language. Once the rules are codified in language, we become able to evaluate them, compare them one to another, and debate about whether the codified rule is aligned with what we think was the 'intent' of those who established it. Reason enables continuous dialog about the utility and interpretation of our articulated rules, and how they might be improved to be aligned better with other codified and abstract rules that the social group accepts (Hayek, 1976).

Now we come to the crux of the issue that Hayek was addressing. The primary target of Hayek's analyses was the creativity-stifling effect of attempts to centrally plan economic activities and outcomes. He wanted to demonstrate that central planning will always and everywhere be incomplete and will always lead to social and economic stagnation because it is not reason that creates new rules to deal with new circumstances. Rather, Hayek asserts, new rules that lead to unexpected, novel human activity and outcomes emerge between instinct and reason. It is only after the new practices have emerged that human reason is engaged in the codification, modification, and comparative evaluation of rules that promote the new practices.

Hayek's analysis can also be applied to the challenges of nurturing a creative corporate culture. It is important to remember that human adaptation to new circumstances requires creativity and cannot be achieved in advance through the application of reason. In other words, just as central planning of an economy cannot be successful in nurturing creativity because central planning inhibits creativity on the frontier; central planning also cannot be successful in nurturing creativity within the context of the corporation because that also occurs on the frontier. In short, creativity cannot be imposed by fiat or executive order, and it cannot be planned in advance. The creative corporation will only result from careful cultivation of the conditions under which creativity can naturally emerge. Still, corporations must have some codified rules. The notion of a corporation without formal, governing rules is not just an odd concept, it is literally undefined. Unlike a society, however, where many of the abstract rules that people follow are a result of many generations of trial and error learning leading to abstract rules and traditions that have proven to be useful, the average corporation doesn't have as long a history of such learning. So how can the corporation establish a culture bounded by abstract rules, but at the same time allows for creativity between instinct and reason that Hayek cites as the key to what he calls the 'spontaneous order'? (Hayek, 1988, p. 146).This is the challenge that lies at the heart of nurturing a creative corporate culture. The creativity that contributes to the long-term health and success of the corporation must be constrained within the boundaries of the abstract and formal rules of the corporation. How do people develop an ability to work within the constraints of the rules that govern the daily activities of the corporation and yet preserve the potential to invent 'on the frontier'? 
The consequences that result from people freely acting in accord with abstract rules is referred to as 'spontaneous order'. The notion of something 'spontaneous' occurring within the boundaries of the corporation may seem counter-intuitive to most managers and corporate leaders, but it is the essence of creativity. If corporations want to increase their creative capacity, they must allow for spontaneous order to emerge within the context of appropriate abstract rules. By definition, if spontaneity is stifled, creativity cannot and will not occur. If creativity were not spontaneous then it could be planned in advance and we would not have a need for research to understand and promote corporate creativity.

The spontaneous order is the term that Hayek uses to describe what he calls the "Open Society". (Hayek, 1976, p.112). The astounding capacity for human beings to live freely and in relative harmony by following abstract rules is a recent discovery. Prior to the discovery of the power of individual freedom and the spontaneous order human beings were governed by the whims of monarchs or dictators. The assumption behind this type of social structure is that everyone should pursue the same ends. That is, the 'glory of the state' or the 'glory of the monarchy' were deemed to be the supreme values to which all subjects must contribute and/or submit.

The advent of human liberty on the societal scale was the result of the revolutionaries in the United States and France, mostly in the $18^{\text {th }}$ century. These revolutionaries ushered in a new era in which human beings became free to decide what is best for them as individuals or as family units within the boundaries of abstract rules. This new era of individual liberty precipitated an explosion of creativity, prosperity, and a standard of living that the world had never seen before.

The rise in the general standard of living was a direct result of unlocking the creative powers of every individual within society. Although these creative powers were unleashed to enable each person to pursue their own interests within the context of abstract rules, the unintended consequence was a flourishing of wealth for everyone participating in the free societies. The spontaneous order created by this unleashing of human creativity was not planned by anyone, and, importantly, it could not have been. There is no way a centralized planning authority could have acquired all of the knowledge that collectively resides within the minds of the free individuals acting according to their own interests (Hayek, 1978, p. 23).

As the spontaneous order of the Open Society is arguably the most powerful creative engine humans have ever stumbled upon, it seems likely there are lessons in the key elements of the Open Society for corporate creativity. Nurturing a culture that enables what we will call a 'bounded spontaneous order' seems to be a matter of the prevailing abstract rules and inherent capacities of the employees. As we noted above, merely providing 'tinkering time' is insufficient to promote corporate creativity. In the next section, we will explore some of the findings from the scholarship into expert entrepreneurs. It is argued that corporate creativity will be enhanced if employees are trained and allowed to practice some of the behaviors, attitudes, and principles of the expert entrepreneur to increase corporate creativity.

\section{Conclusions and Action Items}

Significant take-aways can be developed from the above discussion only if you, the reader, have been convinced that the notions of 'effectuation', 'abstract rules', and 'spontaneous order' have been developed sufficiently that harboring doubts is counter-productive. In order to move forward and make the necessary adjustments to nurture a more creative corporate culture, it is imperative that leaders thoroughly absorb and accept these discoveries and overcome any lingering predilections toward maintaining the status quo. There can be no half-measures toward this end. Employees will either be granted the freedom and appropriate empowered to create a bounded spontaneous order, or they will not.The definition of creativity that we discussed above requires absolutely that people are given latitude to explore creative ideas on the frontier.

Of course, maintaining the status quo is the safe and traditional route followed by most large corporations. Careers often are made or broken by decisions to try something new. The concepts discussed in this paper decidedly are new, and they only recently have been applied to the corporate setting. In this era where innovation has been cited as a key source of competitive advantage, it seems that corporations cannot afford to ignore the breaking research and insights into the factors associated with creativity. This paper has explored both best practices, which can be imported immediately, as well as some leading-edge insights into creativity from the perspective of social systems, writ large. 
So, given that you've been warned and given the reasonable assumption that you've read this paper to learn something about how to transform the creative capacities and culture of the enterprise, the following prescriptions are offered:

1.Provide clear decision or resource rights: Entrepreneurs using effectual logic and the entrepreneurial method begin with the resources them currently control. They then act creatively to manage risk and increase returns using these resources.

2. Reward unexpected results and positive returns: There may be no management bromide that is more anathema to corporate creativity than the old 'management by objectives' (MBO). MBO was developed by management guru Peter Drucker and that may in itself be reason enough that the approach will be exceedingly difficult to supplant. Managers love goal setting, and employees love knowing exactly what they need to do to receive their next raise or promotion. In fact, people need objectives and goals to establish the state of flow that we discussed earlier in this paper. Still, it is possible that corporations have taken goal setting to an unhealthy extreme and it is time to step back to enable the spontaneous order to develop.

3.Accept failure as a step in the creative process: Perhaps the most difficult management challenge for nurturing a creative corporate culture is to accept failure as a part of the creative process. Failure is common among entrepreneurs and is generally regarded as a favorable thing if the failure occurred in the context of committed hard work and personal integrity. Entrepreneurs accept the unpredictable nature of the projects they undertake and are capable of cutting their losses and moving on to the next project in the event of a failure. Contrariwise, a well-known problem in management is the so-called 'escalation of commitment' phenomenon that occurs when people feel a project is failing (Staw, 1981). Rather than cutting their losses and accepting failure they tend to escalate commitment in the hope that they eventually will succeed. 'Hope' as a strategy is not something that entrepreneurs choose to do. Hope also should not guide strategy within the corporation. Creativity naturally engenders failure. Corporations need to find a way to set clear guidelines for knowing when to accept failure, and when to forge ahead in the event that success is right around the corner. For the entrepreneur, failure is reached when the affordable loss they are willing to accept has been exceeded. Something similar needs to become a part of corporation projects. In a recent and very rare magazine interview, marketing guru Seth Godin said:"How many people go to work each day and say 'This might not work' and then go do it? The answer is, not enough" (Brown, 2013).

4. Take charge of the 'abstract rules': As we discussed, no formal rules can be written to nurture corporate creativity. Corporate creativity must occur between instinct and reason, and it will be governed and channeled by 'abstract rules'. We all know what the abstract rules are in any particular workplace. Normally, within the corporate setting, it is evidenced by the phrase "that's the way we do things around here". The abstract rules that employees follow are created by what leaders do and say, not by the formal rules they create and/or enforce. Most of the formal rules in corporations are of the 'thou shalt not' variety. They do not usually promote the kind of corporate creativity that we are seeking via this brief analysis. Only the abstract rules that enable creative pursuit of ends that are unpredictable in the present will promote the kind of hard work and toil that precedes genuine instances of creativity. It is vital that the organization have skilled managers that can promote a culture that empowers employees to use their creativity. Such promotion is a result of deeds, not directives. People cannot be directed to 'be creative'. Managers must be trained to enable the spontaneous order via their daily deeds that are examples of the abstract rules that apply to everyone within the organization.

$\mathrm{n}$ this paper we have explored a definition of 'creativity', examined some generally accepted 'best practices', and ventured into new domains by linking Hayek's analysis of the greatest single engine of human creativity free market economics to the corporation. The recipe for nurturing a culture of creativity in the organization certainly includes some or perhaps all of the best practice ingredients that we examined here. However, this paper also argued that simply importing these ingredients into the average corporate environment will be insufficient to nurture creativity. What is generally missing is an empowering framework where employees are not merely left alone to 'be creative' (as in the 'tinkering time' approach that has been shown generally to be ineffective), but actually empowered to be creative within the context of firm-specific abstract rules.

In addition to preparing employees for creativity, managers and leaders can prepare themselves to be comfortable with an evolving spontaneous order. As a caveat, this paper acknowledges that corporations cannot be as freeform as Hayek's Open Society, and that in the corporate setting a 'bounded spontaneous order' is preferred instead. 
This can be managed through developing and promulgating the appropriate set of 'abstract rules'. Whether these are communicated via technical terminology such as 'hurdle rates'; or whether the abstract rules are communicated less directly via leadership actions is an important consideration. Formal rules are generally of the 'thou shalt not' genre, and hardly conducive to promoting corporate creativity. Instead, employees need to have a firm idea of the resources they legitimately control, the boundaries within which these resources can be leveraged, and then be allowed to create a new spontaneous order one that is not planned in advance.

Unfortunately, the formality of most corporate structures often precludes such spontaneity, but it would occur naturally under sufficiently well-known abstract rules if managers and leaders would allow it. Corporate leaders must get their arms around the prevailing corporate lore-'the way things are done around here'-in order to nudge the abstract rules toward a more favorable creative culture. Ultimately, those leaders who desire to nurture a more creative corporate culture must, ironically, learn to 'let go' in order for a bounded spontaneous order to emerge. Continuous creative advantage can be won, but it won't be won by directly ordering it or planning for it.

\section{References}

Brown, C.(2013).The guru takes flight. Entrepreneur, 41, 32.

Csikszentmihalyi, M. (1990). Flow: The psychology of optimal experience.New York:Harper \& Row.

Day, D. (2010). The difficulties of learning from experience and the need for deliberate practice.Industrial \& Organizational Psychology, 3, 41-44.

Duening, T.N.(2007). Enterprise process innovation: The ingredients are well known, but what is the recipe?'International Journal of Innovation and Technology Management, 4, 87-101.

Duening, T.N., \& Ivancevich, J.M. (2001). Managing Einsteins:Leading technical workers in the digital age. New York:McGraw-Hill.

Ekvall, G. (1996). Organizational climate for creativity and innovation. European Journal of Work and Organizational Psychology, 5, 1-5.

Ericcson, K.E., Prietula, M.J., \& Cokely, E.T. (2007). The making of an expert.Harvard Business Review, $85,114-121$.

Finkle, T.A. (2012). Corporate entrepreneurship and innovation in Silicon Valley: The case of Google, Inc. Entrepreneurship: Theory \& Practice, 36, 863-884.

Foege, A. (2013). The tinkerers: The amateurs, DIYers, and inventors who make America great. New York: Perseus Books.

Hayek, F. (1973). Law, legislation, and liberty.Volume 1:Rules and order. Chicago: University of Chicago Press.

Hayek, F. (1948). Individualism and economic order.Chicago: University of Chicago Press.

Hayek, F. (1976). Law, legislation, and liberty. Volume 2: The mirage of social justice. Chicago: University of Chicago Press.

Hayek, F. (1978). New studies in philosophy, politics, economics, and the history of ideas. Chicago: University of Chicago Press.

Hayek, F. (1988). The fatal conceit: The errors of socialism. Chicago: University of Chicago Press.

Koch, C.G. (2007). The science of success: How market-based management built the world's largest private company. Hoboken, NJ:John Wiley \& Sons.

Murphy, T. (1984). Eureka!Forbes, 133, 218.

Painter, K. (2012). Texting, music put distracted pedestrians at risk.USA Today, December 13.

Staw, B.M. (1981). The escalation of commitment to a course of action.Academy of Management Review, 6, 577587.

Von Mises, L. (1949). Human action: A Treatise on economics. New Haven, CT: Yale University Press. 